\title{
Existence of Periodicity in Radon Concentrations and in the Large-Scale Circulation at Lower Altitudes between $40^{\circ}$ and $70^{\circ}$ South \\ Gérard LAMBert
}

\author{
Centre des Faibles Radioactivités, Centre National de la Recherche Scientifique, \\ Gif-sur-Yvette, France \\ Georges Polian
}

Terres Australes et Antarctiques Françaises, Paris, France

D. TAUPIN

Physique des Solides, Faculté d'Orsay, France

\begin{abstract}
South of $40^{\circ} \mathrm{S}$, the proportion of continental areas not covered by water (oceans or antarctic ice sheet) is very small. Thus, the atmospheric concentration of radon measured either in the middle of oceans or at stations on the antarctic continent is the result of the action of all phenomena able to change the large-scale circulation at low altiude. An analysis of the results obtained hour by hour for 2 years in three subantarctic or antarctic stations clearly shows for each of them a 28-day periodicity that cannot be found north of the fortieth parallel. The authors present a first interpretation of this phenomenon.
\end{abstract}

\section{INTRODUCTION}

Radon originates from the soil of continents, and its concentration in the lower layers of the atmosphere depends primarily on the atmospheric stability. Generally, the concentration decreases exponentially with altitude, i.e., from 50 to $100 \mathrm{pc} / \mathrm{m}^{3}$ at ground level to a few $\mathrm{pc} / \mathrm{m}^{3}$ above $2 \mathrm{~km}$ [Kirichenko, 1962; Ba Cuong et al., 1967; Birot et al., 1968]. This distribution is generally valid over all large continental masses and is greatly altered only in two cases [Servant, 1964; Fontan, 1964]. First, in the presence of a temperature inversion, in the immediate vicinity of the ground, radon concentration may reach $5000 \mathrm{pc} / \mathrm{m}^{3}$; and, second, in winter-time, when the soil is flooded or frozen over vast areas, radon concentration may be less than 10 $\mathrm{pc} / \mathrm{m}^{\mathrm{s}}$.

If we measure radon concentration sufficiently far from a continent, the situation is quite different:

1. The measured concentration no longer depends on purely local meteorological conditions. Even in the Kerguelen Islands, whose

Copyright (C) 1970 by the American Geophysical Union. dimensions attain the order of $100 \mathrm{~km}$, studies have shown that the radon that is produced locally is negligible and that no simple correlation may be established between radon concentration and local meteorological conditions [Lambert and Polian, 1965].

2. On the contrary, radon concentration depends essentially on the circulation pattern of the air masses from the continents to the measuring station. For example, a long transit time will result in lower concentration, owing to decay of radon (half-life 3.8 days). Further, vertical mixing can also alter the radon distribution considerably. Unusually high values of concentration may result from such particular synoptic situations as those which bring the low-level continental air very quickly, without dilution by mixing from upper air. It is clear, therefore, that the concentration of radon in the atmosphere, where it is measured far from continents, is diagnostic of large-scale atmospheric circulation.

\section{Antarctic and Subantarctic Measurements}

Since the end of the International Geophysical Year, stations for measuring radon concentrations have been established at New Amster- 
dam $\left(37^{\circ} 50^{\prime} \mathrm{S}, 77^{\circ} 30^{\prime} \mathrm{E}\right)$, Crozet $\left(46^{\circ} 20^{\prime} \mathrm{S}, 51^{\circ} \mathrm{E}\right)$, the Kerguelen Islands $\left(49^{\circ} 30^{\circ} \mathrm{S}, 70^{\circ} \mathrm{E}\right)$, and Adélie Coast (Terre Adélie, $66^{\circ} 40^{\circ} \mathrm{S}, 140^{\circ} \mathrm{E}$ ) (see Figure 1). The concentration is determined by simply measuring the short-lived decay products of radon.

Since 1967 these stations have been fitted with equipment carrying a large rotating air filter. Every other hour the part of the filter that has been collecting the aerosols is automatically switched over to an $\alpha$ scintillation counter. Through the measurement of $\alpha$ activity decay we can distinguish between the respective contributions of radon 222 and thoron 220 . The utilization of this counter has enabled us to obtain the systematic identification of sharp radon concentration variations (independent of variations of thoron) and, consequently, of local meteorological conditions. The amplitude of variations justifies the neologism of 'radon storms' [Polian and Lambert, 1968]; in the example given in Figure 2, it is clear that radon concentration suddenly rises almost to the continental value of $10 \mathrm{pc} / \mathrm{m}^{3}$. In a few cases, these storms occurred nearly simultaneously in several stations.

Figure 3 shows that the monthly mean radon concentration is also subject to variations; in this example the variation shows a marked seasonal character. In subantarctic stations, the concentration doubles during the winter months, when the atmospheric circulation is more rapid.

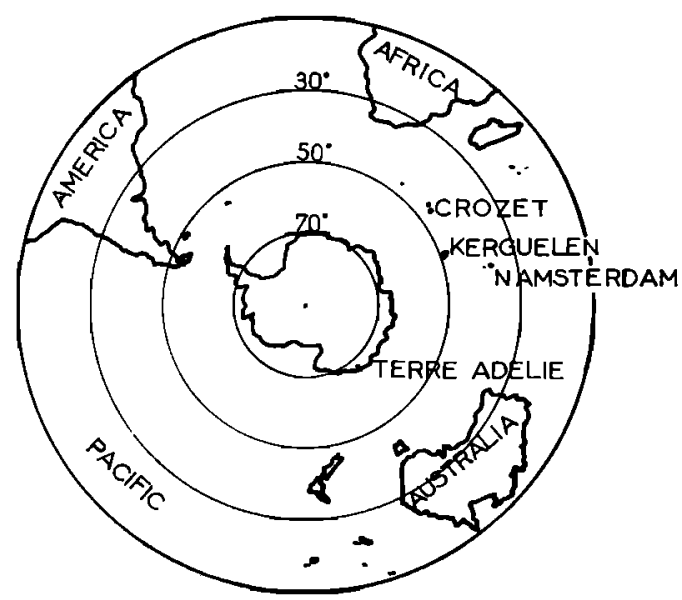

Fig. 1. Map of the Austral French stations in the antarctic area (Crozet, Kerguelen Islands, New Amsterdam, Adélie Coast).

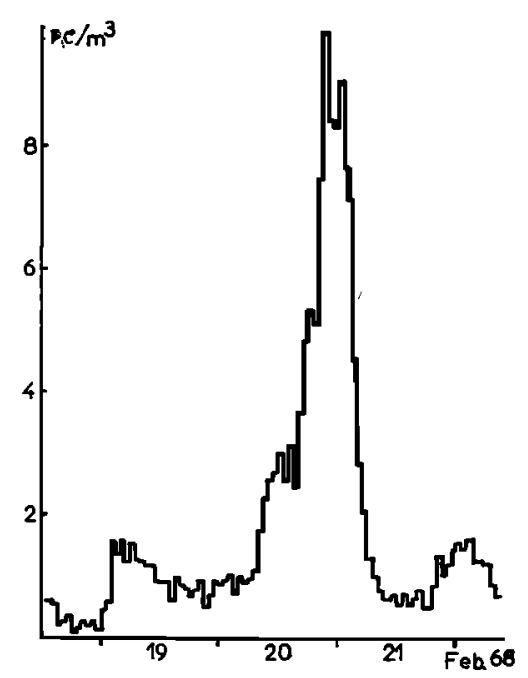

Fig. 2. Example of a 'radonic storm' at Adélie Coast.

For Adélie Coast, however, this increase for winter months is hardly visible. On the contrary, in Adélie Coast for the summer months of December and January, radon concentration increases threefold, up to the Crozet figure; this fact reveals the importance of the penetration into the antarctic continent of northern air masses, probably originating from the southern part of the American continent. (A south African or Australian origin would imply a very unlikely direct meridian transfer.)

\section{Crclic Variation of Radon Concentration}

A thorough study of the radon recordings in any of our stations, with the exception of New Amsterdam, shows a cyclic nature of the observed values with a period of about one month.

To specify this phenomenon, the recordings were analyzed by two methods, the periodogram and the Fourier transform. In the periodogram method, the a priori assumption of the existence of an $n$-day period is made. The analyzed period is split into series of $n$ days. Then the mean values for the 1 st, 2 nd, $\cdots$, nth days are worked out. A similar calculation is made for each possible period between 1 and 70 days. This method has the drawbacks of being insensitive and of delivering simultaneously multiples of the fundamental period. The Fourier 


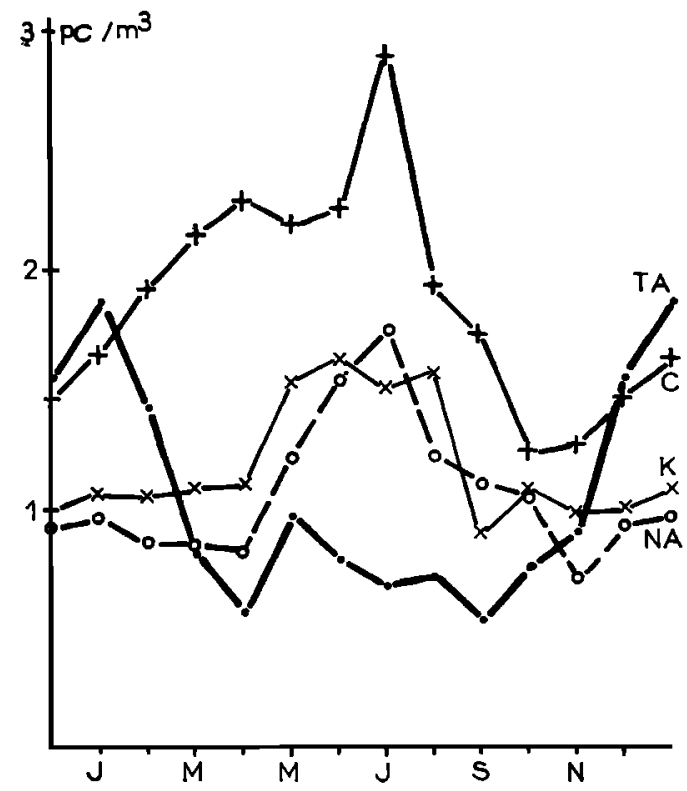

Fig. 3. Monthly mean radon concentrations (1967-1969); $N A$, New Amsterdam; $C$, Crozet; $K$, Kerguelen; $T A$, Terre Adélie (Adélie Coast)

transform method is a classical, well-known tool. It is very sensitive, but it has the disadvantage of being perturbed by the splitting of the time interval under study.

In the course of this analysis, the following three precautions were taken:

First, the duration of each time span to be analyzed was limited to 6 months so as to limit the effect of possible stochastic shifts. However, the results remain essentially unaffected when the analyzed interval lasts longer than a year. Moreover, these 6-month intervals have only a 3-month shift between them. Eventually, the calculations were worked out again after a shift of a few days in order to check that the results did not show any casual trend.

Second, the complete calculations were made not only on the original data but also on such data as had been multiplied by a Gaussian function, to eliminate edge effects. They were also worked out again for such data as had been corrected for the mean of the interval starting 15 days before and ending 15 days after the measurements, to cancel the aforementioned seasonal effects.

Third, a similar calculation was undertaken on purely stochastic data that had the same mean value, distribution, and failure intervals as the observed data. Thus, the splitting effects due to possible failures are identical.

Figure 4 shows the curves obtained by the two methods at the Crozet station from March 25 to October 16, 1968, from the original data, the corrected data, and the stochastic figures. Figure 5 sums up the results obtained by the Fourier transform in four of the favorable cases for data corrected for the mean seasonal effect in the stations of Kerguelen Islands and Adélie Coast. Several periods appear on the diagram for the Kerguelen, Crozet, and Adélie Coast stations. In most cases the main peak corresponds to a period of 28 days. This result clearly appears in Figure 6, which shows the frequency of appearance of each period during the duration of our study (2.5 years). The 28day period is dominant and is associated with the values corresponding to the second and fourth harmonics. Beyond 28 days, no significant period can be found. At the New Amsterdam station, no periodicity is apparent.

Thus, it may be concluded that, in the antarctic and subantarctic regions, the radon concentration in the atmosphere and, hence, the large scale atmospheric circulation, present cyclic variations with a period of 27 to 28 days. Nevertheless, the following two remarks should be made: (1) A first analysis does tend to show that other scalar parameters of the atmosphere present a similar cyclic nature. Such is the case for the barometric pressure at the Kerguelen Islands; and (2) Although the cyclic character is well established for most 6-month intervals, it may happen that it completely vanishes at one of these stations. Conversely, it may appear on occasion at New Amsterdam.

\section{INTERPRETATION}

If the existence of a 27- to 28-day period is an experimentally established fact, the interpretation that we may venture is at present only a hypothesis. One cannot fail to be struck by the similarity between this period and the recurrence period (also 27 to 28 days) of the solar component of cosmic rays, revealed by the same periodogram method as used here, and attributed to the rotation of subequatorial zones on the surface of the sun. This interpretation 


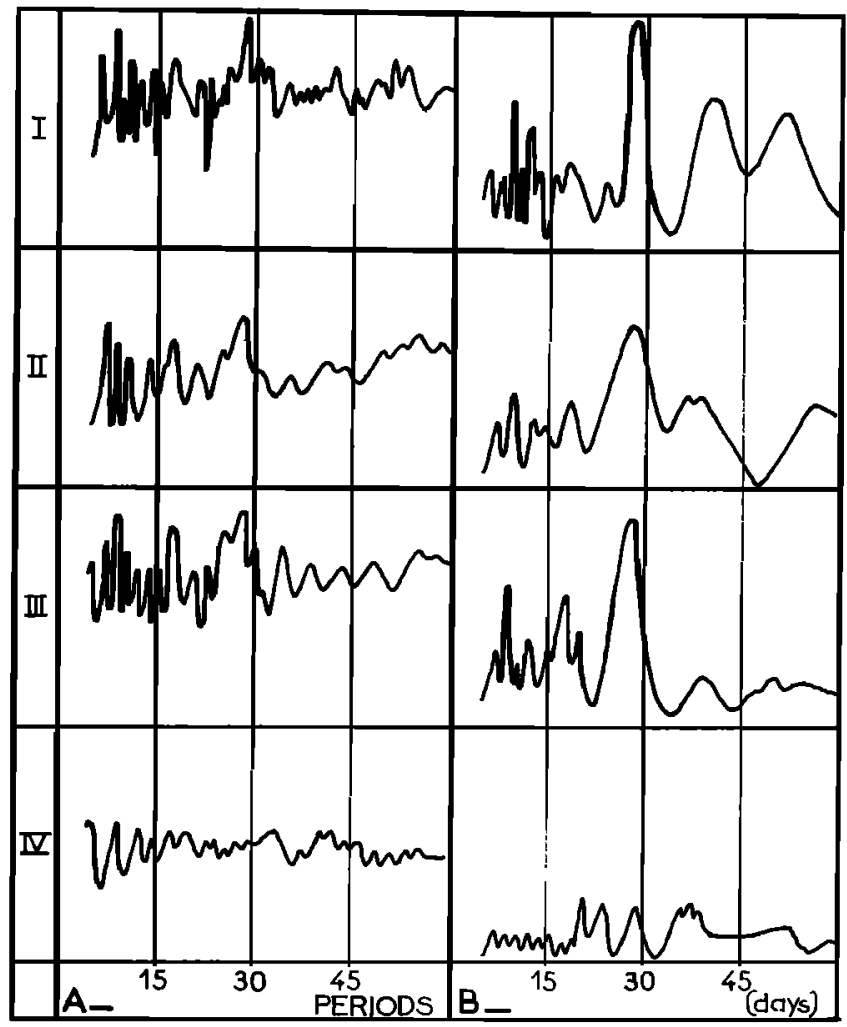

Fig. 4. Crozet: April 4-August 21, 1968; $A$, periodogram; $B$, Fourier transform; I, original data; II, multiplied by a Gaussian function; III, correction of seasonal variations; IV, stochastic data.

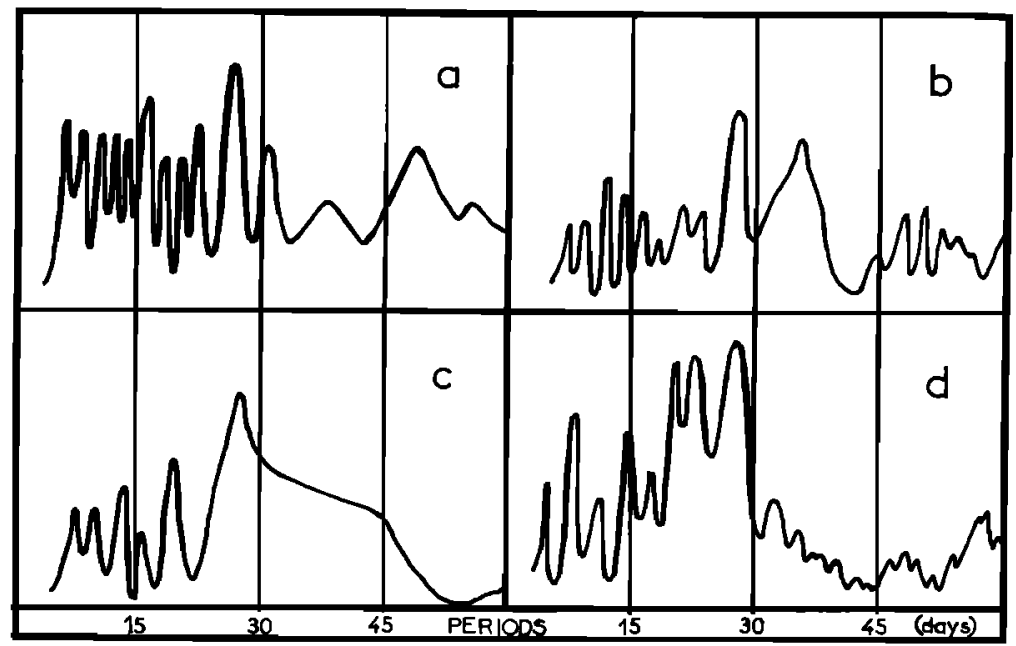

Fig. 5. Fourier transform corrected for the mean seasonal effect: $a$, Adélie Coast, second half of 1967; $b$, Adélie Coast, second half of 1968; $c$, Kerguelen, first of 1967; $d$, Kerguelen, first half of 1968 . 


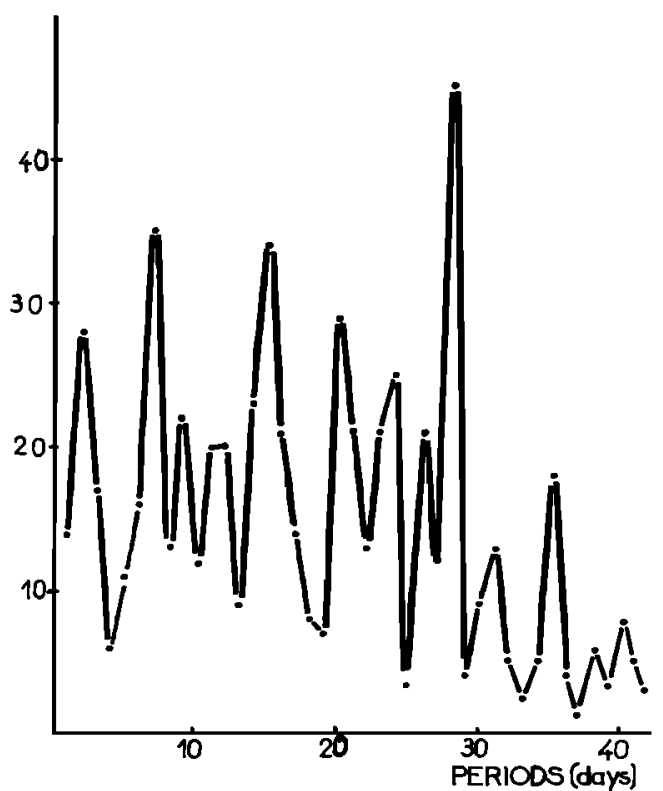

Fig. 6. Curve of frequency of appearance at different periods (for all data, Kerguelen, Crozet, Adélie Coast).

assumes that the corpuscular radiation (which constitutes only a very small part of the energy yielded by the sun) can, nevertheless, influence the general circulation even at a low altitude. No satisfactory model has yet been generated to explain such an influence. However, a similar hypothesis has been formulated by several geophysicists, including Lambert et al. [1965, 1966], to explain the cyclic variations, of an 11-year period, in lead 210 distribution in antarctic snow. Mustel [1968] has also presented a complete theory that is aimed at explaining the correlations he observed between the major solar flares and the distribution of barometric pressures at low altitudes.

These major flares have an energy that is very much higher than that of recurrent phenomena. Any action of these recurrent phenomena on atmospheric circulation could be ex- plained only if the solar particles triggered a more complex mechanism than that put forward by Mustel.

\section{REFERENCES}

Birot, A., J. Fontan, S. Adroguer, D. Blanc, and A. Bouville, Mesures de la concentration du radon dans la troposphère, Commun., Colloq. Electron. Nucl. Radioactiv., Toulouse (France), March 1968.

Fontan, J., Dosage des radioéléments gazeux donnant des produits radioactifs de filiation; son application à la mesure de la radioactivité naturelle de l'atmosphère, Thesis, Faculté des Sciences de Toulouse, France, 1964.

Kirichenko, L. V., The vertical distribution of the products of decay of radon in the free atmosphere, in Problems of Nuclear Meteorology, edited by I. L. Karol and S. G. Malakhov, pp. 92-124, Eng. Transl., AEC tr-6128, Moscow, 1962.

Lambert, G., and G. Polian, Etude de la radioactivité naturelle aux iles Kerguelen et en Terre Adélie, Rev. Centre Nat. Rech. Sci., 12, 4-35, 1965.

Lambert, G., M. Nezami, and J. Labeyrie, Correlations entre le dépôt de ${ }^{20} \mathrm{~Pb}$ dans l'Antaretique et l'activité solaire, Comptes Rendus, 260, 619622, Paris, 1965.

Lambert, G., B. Ardouin, M. Nezami, and G. Polian, Possibilities of using ${ }^{10} \mathrm{~Pb}$ as an atmospheric tracer, Tellus, 18, 421-426, 1966.

Mustel, E. R., Flux solaires corpusculaires et leur influence sur l'atmosphère de la Terre, French Transl. Acad. Astron. URSS, 10, pp., 3-174, Moscow, 1968.

Cuong, Nguyen Ba, G. Lambert, G. Polian, and J. P. Jacquin, Comparaison des distributions verticales du Radon 222 de 0 à $4500 \mathrm{~m}$ au-dessus de l'Atlantique, du continent Antarctique et de la région parisienne, Comptes Rendus, 265, 1065-1068, Paris, 1967.

Polian, G., and G. Lambert, Orages radioniques en Terre Adélie, Commun. Colloq. Electron. Nucl. Radioactiv., Toulouse (France), March 1968.

Servant, J., Le Radon et ses dérivés à vie courte dans la basse atmosphère, Thesis, Faculté des Sciences de Paris, France, 1964.

(Received November 12, 1969; revised January 6, 1970.) 